\title{
Association of Helicobacter pylori and Coronary heart disease in Iran: A meta-analysis
}

\author{
Yousef Rahmani ${ }^{1}$, Sareh Mohammadi ${ }^{2}$, Hossein Karim², Mahin Rezazadeh ${ }^{1}$, Mehran Babanejad ${ }^{2}$, \\ Afshar Shahmohammadi*1, Alireza Rai ${ }^{2}$
}

\section{Abstract}

Background: Several studies in the recent decade have supported a relationship between different types of infections and CHD (Coronary Heart Disease); however, such a relationship is not definitely proven. Helicobacter pylori is one of the most common infections in human. The role of inflammation in the pathogens of CAD (Coronary Artery Disease) has been widely discussed; although, the mechanism is not clearly known yet.

Methods: In this systematic review and meta-analysis all case-control articles on the relationship between Helicobacter pylori and CHD published from 31st June 2000 to 31st June 2016 indexed in Scopus, PubMed, Google Scholar, Science Direct, and Iranian databases Magiran, Iran Medex, Irandoc, and SID were included. The articles were searched using the following keywords in Farsi and English. The extracted data was imported into Microsoft Excel and analyzed in Stata 12.

Results: Thirty case-control studies conducted in different regions of Iran (15 provinces) have been published from 2001 to 2015 included in this study. A general estimate of OR (Odds Ratio) for the association of Helicobacter pylori and heart diseases in Iran was 2.351 (95 CI: $(1.715,3.221)$ ).

Conclusion: According to the observed association between Helicobacter pylori and heart diseases in the resent study, most of the hosts of the bacterium are afflicted with the infection in their childhood. Therefore, personal hygiene promotion and preventive programs for Iranian children may have a considerable role in reducing the risk of the infection and cardiovascular diseases, consequently.

Keywords: Coronary heart disease, Helicobacter pylori, Iran, Meta-analysis

Copyright@ Iran University of Medical Sciences

Cite this article as: Rahmani Y, Mohammadi S, Karim H, Rezazadeh M, Babanejad M, Shahmohammadi A, Rai A. Current status of health index in Tehran: A multidimensional approach. Med J Islam Repub Iran. 2018 (17 Aug);32:73. https://doi.org/10.14196/mjiri.32.73

\section{Introduction}

Several studies in the recent decade have supported a relationship between different types of infections and CHD (Coronary Heart Disease); however, such a relationship is not definitely proven. Bacteria such as Helicobacter pylori have been found effective on the development of atherosclerosis $(1,2)$. Prevalence of Helicobacter pylori infection in Iran exceeds $80 \%$; although, this rate has started a declining trend in the recent years (3). There is a mutual relationship between the infection and hygiene condition in the society, so that prevalence of the infection is high in

Corresponding author: Afshar Shahmohammadi, afsharshahmohammadi@yahoo.com

1. Clinical Research Development Center, Imam Ali and Taleghani Hospital, Kermanshah University of Medical Sciences. Kermanshah, Iran.

2. Cardiovascular Research Center, Kermanshah University of Medical Sciences, Kermanshah, Iran. the developing countries including Iran.(4).

The role of inflammation mechanism in pathogens and progress of CAD (Coronary Artery Disease) has been widely discussed; although, the mechanism is not clearly known yet. It is believed that the chronic inflammation caused by chronic infections (e.g. Helicobacter pylori) may result in advanced atherosclerosis and CAD consequently (2). Raijasekhar et al. showed in their study that high levels of C-reactive protein, lipids, lipoproteins, and coronary risk factors in the patients with unstable angina

$\uparrow$ What is "already known" in this topic:

Several studies have reported a relationship between Helicobacter infection and ischemic heart disease, while some have rejected such a relationship. Since there are no study supporting a definite relationship between Helicobacter pylori infection and Coronary Heart Disease (CHD) in Iran, the present study was conducted to examine this theory.

$\rightarrow$ What this article adds:

The present study showed that there was a strong association between Helicobacter pylori and CHD in Iranian population so that the chance of CHD in patients with Helicobacter pylori was twofold higher than healthy people. 
and positive Helicobacter pylori indicated that the pathogen may affect the risk factors of coronary arteries and had a role to play as a pathogen of atherosclerosis. Tamura et al. carried out a study in Japan and reported that Helicobacter pylori infection led atrophic gastritis into a chronic disease, which in turn reduced vitamin B12 in the plasma and folic acid level. These changes result in an increase in homocysteine level, which is a risk factor for atherosclerosis (5-7).

Several studies have reported a relationship between Helicobacter infection and IHD, while some have rejected such a relationship (8-11). Mandell et al. were the first group to examine the relationship between Helicobacter pylori infection and development of CHD and they found a significant relationship between the infection and the disease (12). Danesh and Peto carried out a meta-analysis of 18 epidemiologic studies on 10000 patients and concluded that there was no significant relationship between Helicobacter pylori and CHD (13). Khodaie et al. showed in their study that MI (Myocardial Infarction) was significantly higher in populations with a higher frequency of Helicobacter infection (14).

Given the above introduction and the diversity of the results about Helicobacter infection and coronary diseases, the necessity of carrying out a study to determine coronary disease prevalence in the population with Helicobacter infection is quite clear. Since there are no studies supporting a definite the relationship between Helicobacter pylori infection and CHD in Iran, the present study was conducted to confirm this theory.

\section{Methods}

\section{Search strategy}

In the systematic review and meta-analysis, all casecontrol articles on the relationship between Helicobacter pylori and CHD published from $31^{\text {st }}$ June 2000 to $31^{\text {st }}$ June 2016 indexed in Scopus, PubMed, Google Scholar, Science Direct, and Iranian databases including Magiran, Iran Medex, Irandoc, and SID were included. The articles were searched using the following keywords in Farsi and English. We tried to search titles and/or abstracts of articles published in all mentioned databases, simultaneously. Next, the numbers of searched articles were recorded for each database to calculate the total numbers of searched articles.

"Helicobacter pylori", "H. pylori" combined with "cardiovascular disease", "coronary heart disease", "coronary artery disease", "myocardial infarction", "ischemic heart disease", "arteriosclerotic heart disease", "CHD", "CVD”, or "CAD".

\section{Study selection and eligibility criteria}

Two researchers carried out the search independently and the articles relevant to the purpose of this study were selected based on their title and/or abstract of the articles. In case of disagreement between the two researchers, a third expert assessed the quality of the article. The required data was collected based on the full text of the articles (Error! Reference source not found.). For the selection of the word to search, the population was

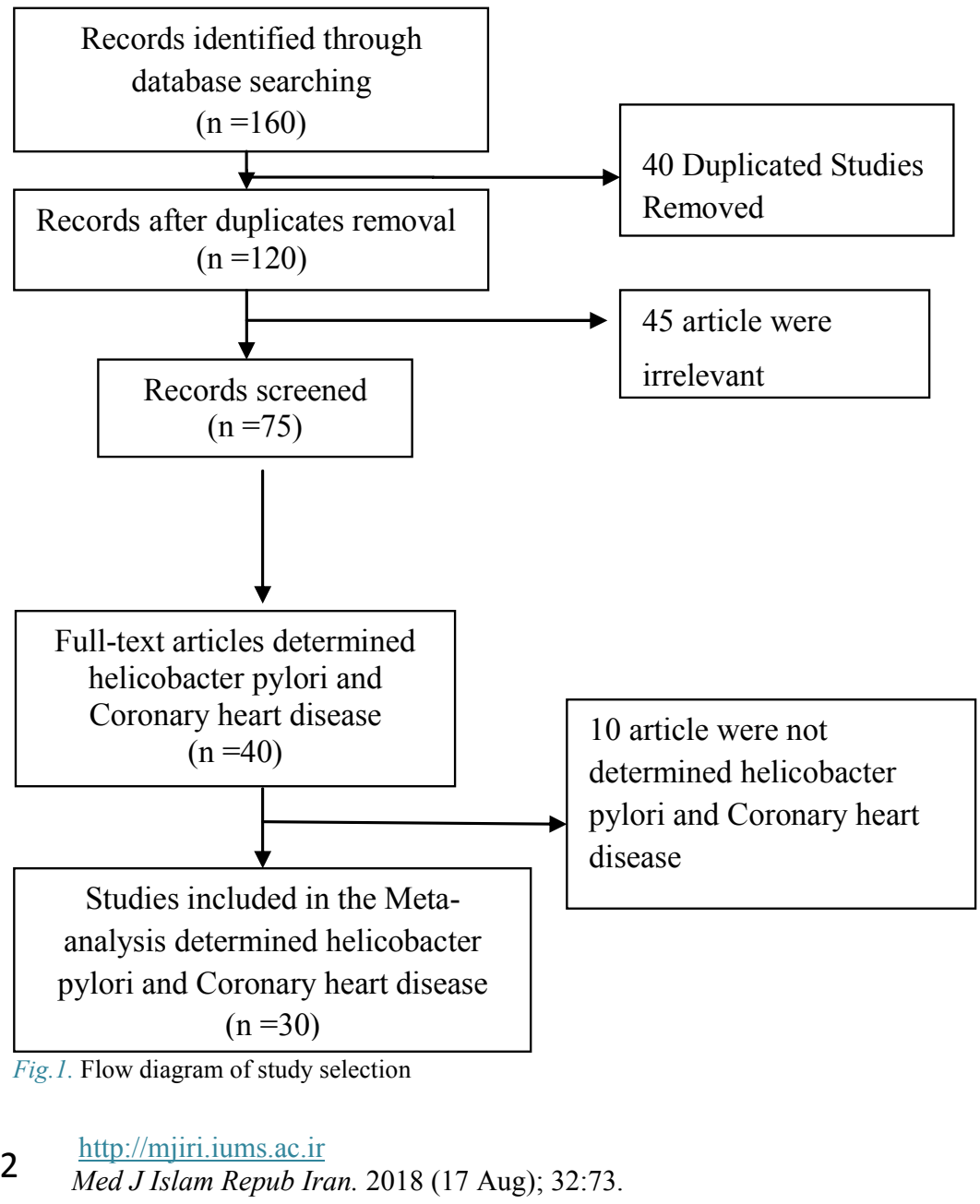


CHD patients, comparisons are the controls do not have $\mathrm{CHD}$, and the outcome was the presence of H. pylori antibodies in two groups.

\section{Inclusion criteria}

Case-control studies, carried out in Iranian cities or provinces, on OR (Odds Ratio) of coronary disease due to Helicobacter pylori infection were the inclusion criteria. In the case of articles available in two languages, the one published in a more creditable journal would be selected. Most of the papers reported IgG and IgA indices to determine helicobacter pylori, while only IgG index was used in this paper as the measure of infection.

\section{Exclusion criteria}

Ecologic, cohort, and cross-sectional studies and those that did not report OR and CI (95\%) or the data to calculate them, and studies reporting unclear data or possible errors were excluded. The author's name or journal's name had no effect on the selection of articles.

\section{Data extraction}

After final assessment of the quality of the papers, the data was extracted using a self-administrated checklist. Then the data were entered into a data extraction sheet in Excel by one person. The checklist included name and surname of the first author, year of publication, place of the study, age/mean age of the subjects, gender, sample size, number of cases and controls, OR and CI (95\%) extracted using IgG in the two groups under study. We included all articles without considering the methods of laboratory testing for $\mathrm{H}$. pylori because our aim was to analyse the total ORs for associations regardless of the clinical methods.

\section{Statistical analysis}

The extracted data were imported and analyzed in Stata 12. Based on the heterogeneity of the study (Cochran's Qtest, Higgins and Thompson's $\mathrm{I}^{2}$ ), two statistical models of fixed effect and random effect $(\mathrm{CI}=95 \%)$ random effects and Der Simonian and Laird methods, sensitivity analysis and Meta-regression method were used for data analyses. To assess the publication bias, Begg's and Egger's tests were used. In addition, sensitivity analysis and Metaregression method were also used.

\section{Results}

Thirty case-control studies conducted in different regions of Iran (15 provinces) have been published from 2001 to 2015 and examined in this study (Table 1). Totally, 6354 participants (3144 cases and 3210 controls) in these studies. Mean and standard deviation age of the case and control groups were 55.82 \pm 4.9 and $53.58 \pm 5.4$ year respectively (Table 2). In addition, 1430 men and 1109 women were in the case group and 1354 men and 1216 women were in the control group (Table 2). The lowest OR was reported by Rahimi F equal to 0.479 (95\% CI: $(0.267,0.86))$ and the highest OR was reported by Eskandarian et al. equal to 21 (95 CI: $(4.45,99.08)$ ).

Based on meta-analysis and the random effects model, general estimate of OR of Helicobacter pylori and heart diseases in Iran was 2.351 (95 CI: (1.715, 3.221)). These OR were different for three heart diseases in different papers. In general, OR of heart diseases was 2.36 , and this

\begin{tabular}{|c|c|c|c|c|c|}
\hline AUTHOR & YEAR & PLACE & CASE & CONTROL & Type of CAD \\
\hline F. Rahimi(15) & 2001 & Tehran & 100 & 100 & Coronary Heart Disease \\
\hline N. Sarrafzadeh(16) & 2001 & Isfahan & 52 & 55 & Myocardial Infarction \\
\hline B. Rahnema(17) & 2001 & Tabriz & 104 & 100 & Myocardial Infarction \\
\hline M. AghaJani(18) & 2002 & Tehran & 100 & 90 & Coronary Heart Disease \\
\hline F. Jalali(19) & 2003 & Babol & 97 & 141 & Myocardial Infarction \\
\hline R. Eskandarian(20) & 2004 & Semnan & 23 & 23 & Cardiac Syndrome X \\
\hline M.A. Bahar(21) & 2004 & Tehran & 131 & 130 & Coronary Heart Disease \\
\hline R. Eskandarian(22) & 2006 & Semnan & 40 & 40 & Cardiac Syndrome X \\
\hline A. Amrai(23) & 2006 & Tehran & 82 & 82 & Coronary Heart Disease \\
\hline F. Raygan(24) & 2006 & Kashan & 50 & 50 & Myocardial Infarction \\
\hline A.H. Faghihi(25) & 2007 & Tehran & 131 & 130 & Coronary Heart Disease \\
\hline A. Pourya(26) & 2007 & Kermanshah & 30 & 30 & Coronary Heart Disease \\
\hline H. Bazazi(27) & 2008 & Gorgan & 109 & 85 & Coronary Heart Disease \\
\hline N. Sarrafzade(28) & 2008 & Isfahan & 57 & 44 & Coronary Heart Disease \\
\hline S.M. Mohammadzadeh.(29) & 2009 & Urmia & 54 & 168 & Cardiac Syndrome X \\
\hline Y. Nozari.(30) & 2009 & Tehran & 70 & 60 & Coronary Heart Disease \\
\hline H. Bazazi(31) & 2009 & Gorgan & 70 & 70 & Myocardial Infarction \\
\hline S. Davoudi(32) & 2010 & Tehran & 69 & 84 & Coronary Heart Disease \\
\hline H. Mirzababaei(33) & 2010 & Tehran & 288 & 294 & Coronary Heart Disease \\
\hline A. Jafarzadeh.(34) & 2010 & Rafsanjan & 60 & 60 & Myocardial Infarction \\
\hline Z. Khodai.(14) & 2010 & Tehran, & 500 & 500 & Myocardial Infarction \\
\hline M. H Khademiansari(35) & 2009 & Tabriz & 100 & 89 & Coronary Heart Disease \\
\hline Z. Azarkar(36) & 2011 & Birjand & 73 & 78 & Myocardial Infarction \\
\hline Y. Rasmi(37) & 2012 & Urmia & 100 & 100 & Cardiac Syndrome X \\
\hline M. Rogha(38) & 2012 & Isfahan & 62 & 43 & Coronary Heart Disease \\
\hline S. Sayyah(39) & 2012 & Qazvin & 40 & 40 & Coronary Heart Disease \\
\hline N. Fouladi(40) & 2012 & Ardabil & 300 & 300 & Coronary Heart Disease \\
\hline H. Honarmand(41) & 2012 & Rasht & 100 & 76 & Coronary Heart Disease \\
\hline J. Vafaeimanesh(42) & 2014 & Qom & 62 & 58 & Coronary Heart Disease \\
\hline N. Dehghan(43) & 2015 & Qazvin & 90 & 90 & Myocardial Infarction \\
\hline
\end{tabular}




\begin{tabular}{|c|c|c|c|c|c|c|}
\hline Variables & $\mathrm{N}$ & Minimum & Maximum & Sum & Mean & Std. Deviation \\
\hline Case & 30 & 23 & 500 & 3144 & - & - \\
\hline Control & 30 & 23 & 500 & 3210 & - & - \\
\hline Age Case & 25 & 42 & 65 & - & 55.82 & 4.9 \\
\hline Age Control & 25 & 41 & 62.4 & - & 53.58 & 5.41 \\
\hline Male Case & 23 & 6 & 260 & 1430 & - & - \\
\hline Female Case & 23 & 14 & 240 & 1109 & - & - \\
\hline Male Control & 23 & 7 & 250 & 1354 & - & - \\
\hline Female Control & 23 & 15 & 250 & 1216 & - & - \\
\hline \multicolumn{7}{|c|}{ Table 3. Disease and Odds Ratio } \\
\hline Disease & & OR & \multicolumn{2}{|c|}{$95 \% \mathrm{CI}$} & $\mathrm{P}$-value & Weight $\%$ \\
\hline Myocardial Infarction & & 2.6 & \multicolumn{2}{|c|}{$(1.313,5.185)$} & 0.001 & $30.75 \%$ \\
\hline Coronary Heart Disease & & 1.7 & \multicolumn{2}{|c|}{$(1.264,2.31)$} & 0.001 & $58.53 \%$ \\
\hline Cardiac syndrome $\mathrm{X}$ & & 8.2 & \multicolumn{2}{|c|}{$(5.003,13.56)$} & 0.475 & $10.72 \%$ \\
\hline Overall & & 2.35 & \multicolumn{2}{|c|}{$(1.7,3.2)$} & 0.001 & $100.00 \%$ \\
\hline \multicolumn{7}{|c|}{ Table 4. Pooled results for 30 case-control studies } \\
\hline Study & & Year & OR & \multicolumn{2}{|c|}{ [95\% Conf. Interval] } & $\%$ Weight \\
\hline Myocardial infarction & & & & Lower & Upper & \\
\hline N. Sarrafzadeh (2001) & & 2001 & 13.219 & 5.096 & 34.292 & 3.05 \\
\hline B. Rahnema (2001) & & 2001 & 3.400 & 1.727 & $6.694)$ & 3.54 \\
\hline F. Jalali (2003) & & 2003 & 0.951 & 0.567 & 1.595 & 3.80 \\
\hline H. Bazazi (2009) & & 2009 & 3.035 & 1.383 & 6.661 & 3.35 \\
\hline Z. Khodai (2010) & & 2010 & 7.765 & 5.829 & 10.344 & 4.09 \\
\hline Z. Azarkar (2011) & & 2011 & 1.788 & 0.891 & 3.590 & 3.51 \\
\hline H. Honarmand (2012) & & 2012 & 2.024 & 0.956 & 4.283 & 3.41 \\
\hline N.Dehghan (2015) & & 2012 & 2.579 & 0.944 & 7.049 & 2.96 \\
\hline F. Raygan (2006) & & 2006 & 0.564 & 0.218 & 1.459 & 3.06 \\
\hline Sub-total (D+L pooled OR) & & - & 2.609 & 1.313 & 5.185 & 30.75 \\
\hline Coronary Heart Disease & & - & - & - & - & - \\
\hline N. Sarrafzade (2008) & & 2008 & 0.829 & 0.219 & 3.136 & 2.41 \\
\hline A. Jafarzadeh (2010) & & 2010 & 4.643 & 1.880 & 11.467 & 3.14 \\
\hline F. Rahimi (2001) & & 2001 & 0.479 & 0.267 & 0.860 & 3.69 \\
\hline M. AghaJani (2002) & & 2002 & 0.897 & 0.478 & 1.683 & 3.62 \\
\hline M.A .Bahar (2004) & & 2004 & 1.663 & 1.019 & 2.712 & 3.84 \\
\hline A .Amrai (2006) & & 2006 & 0.598 & 0.280 & 1.278 & 3.40 \\
\hline A.H .Faghihi (2007) & & 2007 & 1.692 & 1.036 & 2.764 & 3.84 \\
\hline A. Pourya (2007) & & 2007 & 2.750 & 0.934 & 8.100 & 2.83 \\
\hline H. Bazazi (2008) & & 2008 & 2.126 & 0.982 & 4.600 & 3.37 \\
\hline Y. Nozari (2009) & & 2009 & 2.316 & 1.055 & 5.085 & 3.35 \\
\hline S. Davoudi (2010) & & 2010 & 1.034 & 0.543 & 1.971 & 3.59 \\
\hline H. Mirzababai (2010) & & 2010 & 3.435 & 2.443 & 4.831 & 4.03 \\
\hline M. Rogha (2012) & & 2012 & 1.582 & 0.715 & 3.500 & 3.33 \\
\hline S. Sayyah (2012) & & 2012 & 4.889 & 1.809 & 13.211 & 2.98 \\
\hline N.Fouladi (2012) & & 2012 & 1.917 & 1.358 & 2.708 & 4.03 \\
\hline M. Khademiansari & & 2009 & 2.173 & 1.204 & 3.924 & 3.68 \\
\hline J.Vafaeimanesh (2014) & & 2014 & 2.471 & 1.156 & 5.279 & 3.40 \\
\hline Sub-total (D+L pooled OR) & & - & 1.708 & 1.264 & 2.310 & 58.53 \\
\hline Cardiac syndrome $\mathrm{X}$ & & - & - & - & - & - \\
\hline R. Eskandarian (2004) & & 2004 & 11.455 & 2.167 & 60.559 & 1.94 \\
\hline R. Eskandarian (2006 ) & & 2006 & 21.000 & 4.451 & 99.082 & 2.09 \\
\hline S.M. Mohammadzadeh. & & 2009 & 5.726 & 2.701 & 12.138 & 3.41 \\
\hline Y. Rasmi (2012) & & 2012 & 9.036 & 3.966 & 20.584 & 3.28 \\
\hline Sub-total ( $\mathrm{D}+\mathrm{L}$ pooled $\mathrm{OR})$ & & - & 8.237 & 5.003 & 13.562 & 10.72 \\
\hline Overall $(\mathrm{D}+\mathrm{L}$ pooled $\mathrm{OR})$ & & - & 2.351 & 1.715 & 3.221 & 100.00 \\
\hline
\end{tabular}

figure is mean of three OR values for three diseases of cardiac syndrome $\mathrm{X}(\mathrm{OR}=8.2)$, myocardial infarction $(\mathrm{OR}=2.6)$, and Coronary Heart Disease $(\mathrm{OR}=1.7)$; further details are listed in the table below (Table 3).

Odd ratios were obtained based on the number of instances in the case and control groups using the random effects and fixed models. Heterogeneity was determined using $I^{2}$ and Cochran's Q; in addition, heterogeneity test was used to evaluate $\mathrm{H} 0$ so that all the papers were examined as to the same effect. Heterogeneity effect was obtained using $\mathrm{I}^{2}$, which is a measure of inconsistency between the studies and determines if total percentage of changes between the studies is random or due to heteroge- neity; a value of $\mathrm{I}^{2}$ bigger than $50 \%$ indicates heterogeneity among the studies. Here, $\mathrm{I}^{2}$ was equal to $85.6 \%$, $\mathrm{p}<0.001$; therefore, random effects and Der Simonian and Laird methods were used in addition to the sensitivity analysis and Meta regression method.

Combined OR value was 2.35 , which indicates that the OR (of exposure) in the case group was $1.35 \%$ higher than that of the control group $(\mathrm{p}=0.001)$ (Table 4).

Significant publication bias among the included studies (all p>0.05), (Figs. 3, 4).

The random effect model was used to decrease the rate of heterogeneity. We also applied the sensitivity analysis to evaluate the reasons of heterogeneity but the sensitivity

\footnotetext{
$4 \quad$ http://mjiri.iums.ac.ir

Med J Islam Repub Iran. 2018 (17 Aug); 32:73.
} 


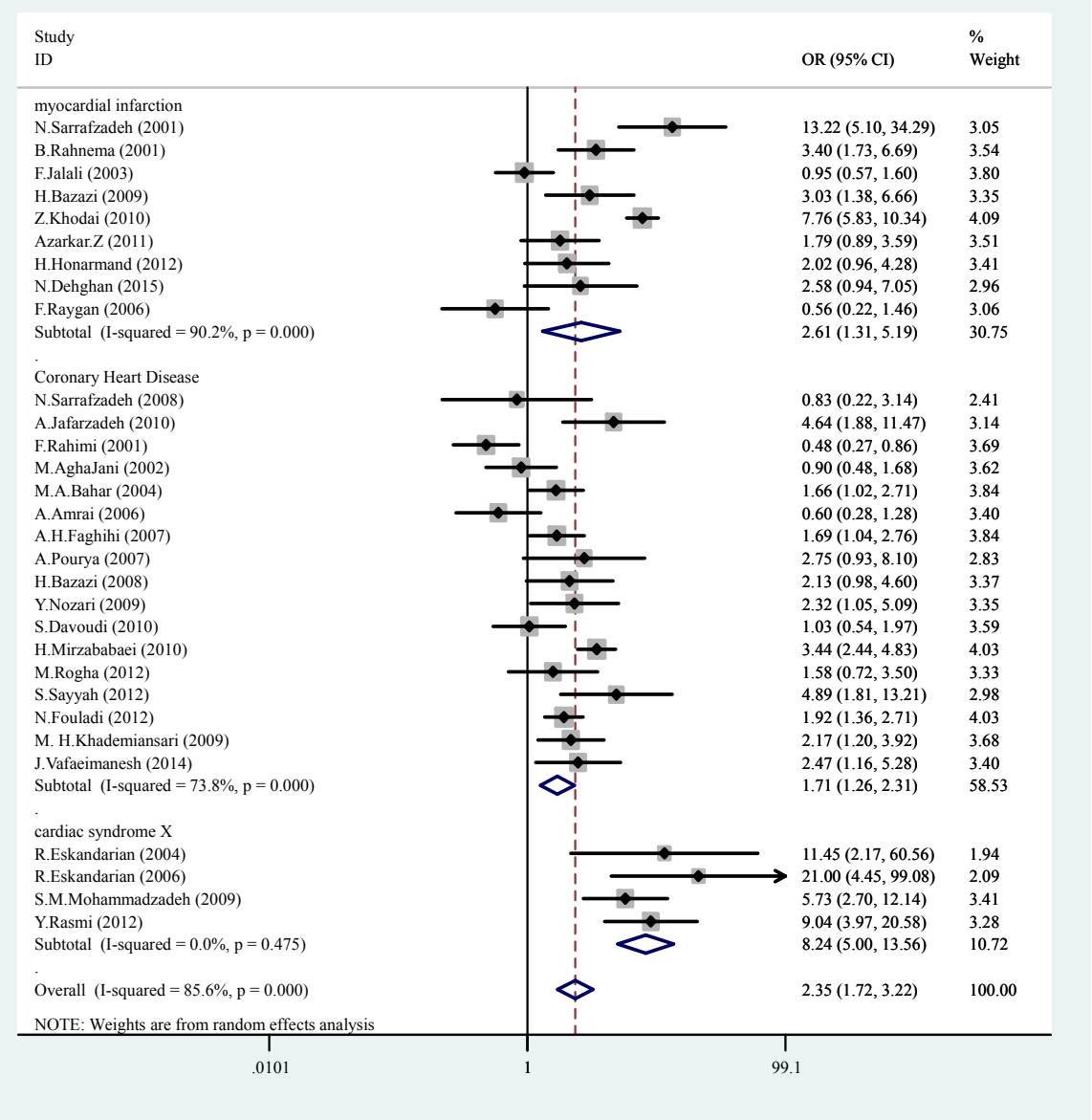

Fig. 2. A forest plot of the association between helicobacter pylori infection and CHD

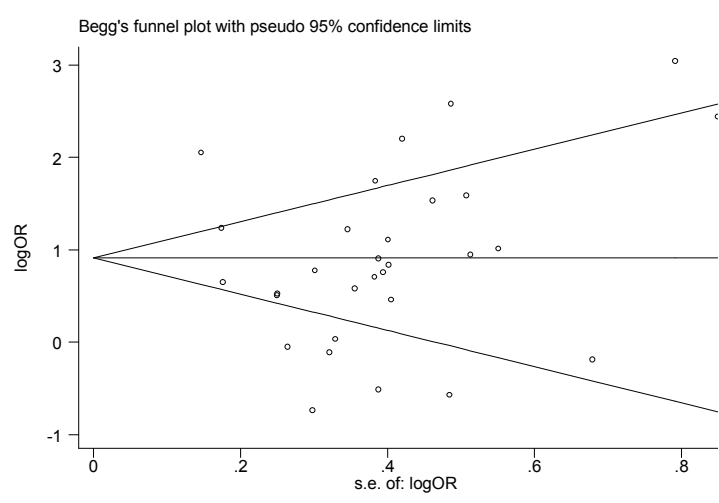

Fig. 3. Begg's Funnel plot with pseudo 95\% confidence limit

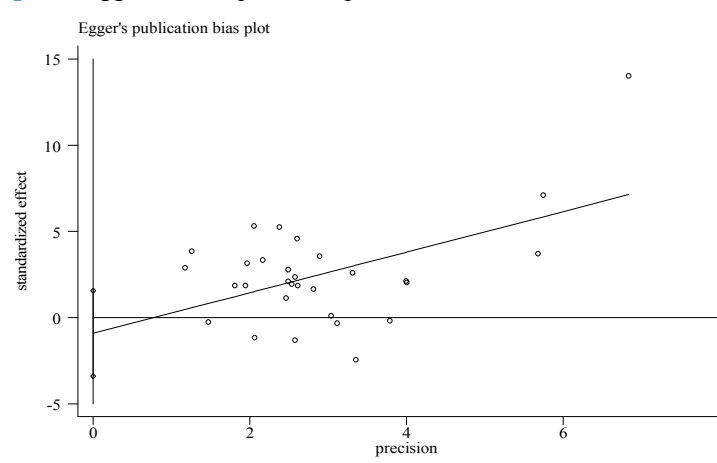

Fig. 4. Eggers publication bias plot geneity. Therefore, we used the Meta-regression method. Variables such as coronary heart disease type, sample size and age of patients were included. Using the Metaregression we evaluated the simultaneous effect of three mentioned variables. Our analysis showed that the rate of variation due to the heterogeneity was decreased up to $53.88 \%$. At the significant level of 0.05 , only the sample size was significant while the variables of sample size, disease 3 and age were significant at 0.1 level of significance (Tables 5-9 \& Figs. 5, 6).

The Meta-regression analysis showed that the OR of having $\mathrm{H}$. pylori had a negative correlation with the age of participants $(\mathrm{p}=0.005)$, (Table 7 , Fig. 5).

\section{Discussion}

The results about the relationship between Helicobacter pylori infection and heart diseases were inconsistent, and despite several studies in this field, one cannot be sure about such relationship. The present study is the only systematic review study in Iran on this topic.

The findings showed that OR of heart diseases in case groups with Helicobacter pylori infection was higher than that of the control group without the infection. Total OR of heart diseases in the case group was 2.35 times higher than that of the control group.

Mendel et al. conducted one of earliest studies on the re-

analysis was not so useful to detect the reason of hetero- 


\begin{tabular}{lccccc}
\multicolumn{2}{l}{ Table 5. Test(s) of heterogeneity } & \multicolumn{5}{l}{} \\
\hline \multicolumn{2}{l}{ Heterogeneity statistic } & Degrees of freedom & P -value & I-squared** & Tau-squared \\
\hline myocardial infarction & 81.56 & 8 & 0.001 & $90.2 \%$ & 0.957 \\
Coronary Heart Disease & 61.15 & 16 & 0.001 & $73.8 \%$ & 0.271 \\
cardiac syndrome X & 2.50 & 3 & 0.475 & $0.0 \%$ & 0.000 \\
Overall & 201.68 & 29 & 0.001 & $85.6 \%$ & 0.610 \\
\hline
\end{tabular}

${ }^{* *}$ I-squared: the variation in OR attributable to heterogeneity), Note: between group heterogeneity not calculated; only valid with inverse variance method Significance test(s) of $\mathrm{OR}=1$

\begin{tabular}{lll}
\hline Myocardial infarction & $\mathrm{z}=2.74$ & $\mathrm{p}=0.006$ \\
\hline Coronary Heart Disease & $\mathrm{z}=3.48$ & $\mathrm{p}=0.000$ \\
cardiac syndrome X & $\mathrm{z}=8.29$ & $\mathrm{p}=0.000$ \\
Overall & $\mathrm{z}=5.32$ & $\mathrm{p}=0.000$ \\
\hline
\end{tabular}

\begin{tabular}{|c|c|c|c|c|c|}
\hline Parameters & Coefficient & Standard errors & $\mathrm{t}$ & $\mathrm{P}>|\mathrm{t}|$ & [95\% Conf. Interval] \\
\hline Disease 2 & -0.42 & 0.25 & -1.66 & 0.112 & {$[-0.94,0.1]$} \\
\hline Disease 3 & 0.9 & 0.43 & 2.06 & 0.053 & {$[-0.01,1.82]$} \\
\hline Sample size & 0.002 & 0.001 & 2.16 & 0.043 & {$[0.001,0.002]$} \\
\hline Age & -0.05 & 0.03 & -1.77 & 0.092 & {$[-0.115,0.009]$} \\
\hline Constant & 3.77 & 1.69 & 2.23 & 0.037 & {$[0.24,7.29]$} \\
\hline \multicolumn{4}{|c|}{ Meta-regression } & \multicolumn{2}{|r|}{ Number of obs $=25$} \\
\hline \multirow{5}{*}{\multicolumn{3}{|c|}{$\begin{array}{l}\text { REML estimate of between-study variance } \\
\% \text { residual variation due to heterogeneity } \\
\text { Proportion of between-study variance explained } \\
\text { Joint test for all covariates } \\
\text { Prob }>\text { F }\end{array}$}} & & \multicolumn{2}{|r|}{$\mathrm{Tau}^{2}=0.155$} \\
\hline & & & & \multirow{2}{*}{\multicolumn{2}{|c|}{$\begin{array}{l}\text { I-squared_res }=53.88 \% \\
\text { Adj R-squared }=66.71 \%\end{array}$}} \\
\hline & & & & & \\
\hline & & & & \multicolumn{2}{|r|}{ Model F(4,20) $=6.57$} \\
\hline & & & & \multicolumn{2}{|r|}{0.0015} \\
\hline
\end{tabular}

lationship between Helicobacter pylori and OR of heart diseases. They studied 111 patients and 74 healthy participants in case and control groups respectively and compared them in terms of Helicobacter infection and risk of heart diseases. They reported that OR of heart diseases in the presence of the infection was two times more than that without the infection (12). Their results are consistent with our results. Their study raised the worries about the probable relationship between Helicobacter infection and heart diseases and followed by several studies conducted in this area in the following years. Inconsistent results have been reported by different studies so that some have found a positive relationship and some have reported no significant relationship between the variables (44). The results of the present review study showed that studies with small sample group reported higher OR of heart diseases in presence of Helicobacter pylori infection. On the other hand, studies with large sample group on controlling the main risk factors of heart diseases found no such relationship (45). To reach a conclusion, all studies conducted in Iran on the relationship between Helicobacter pylori and heart diseases were included regardless of their sample size.

A study based on polymerase chain reaction (PCR) to diagnose Helicobacter pylori infection coronary arteries plaque in patients under coronary artery bypass grafting (CABG) showed that $29.5 \%$ of the surgery patients had positive Helicobacter pylori infection culture. Serology evidences of infection were observed in $53.3 \%$ of 105 patients. Therefore, Helicobacter pylori infection was effective on raptured plaque and development of the coronary ischemic disease. It is believed that chronic inflammation caused by chronic infections may lead to the development of advanced atherosclerosis and CAD consequently $(46,47)$.
The results showed that OR of MI in people with Helicobacter infection was 2.5 times more than individuals without the infection $(48,49)$. Results of one of the few studies conducted as a systematic review work at international level to examine the relationship between Helicobacter pylori infection and MI indicated that OR of MI in patients with this type of infection was 1.73 times
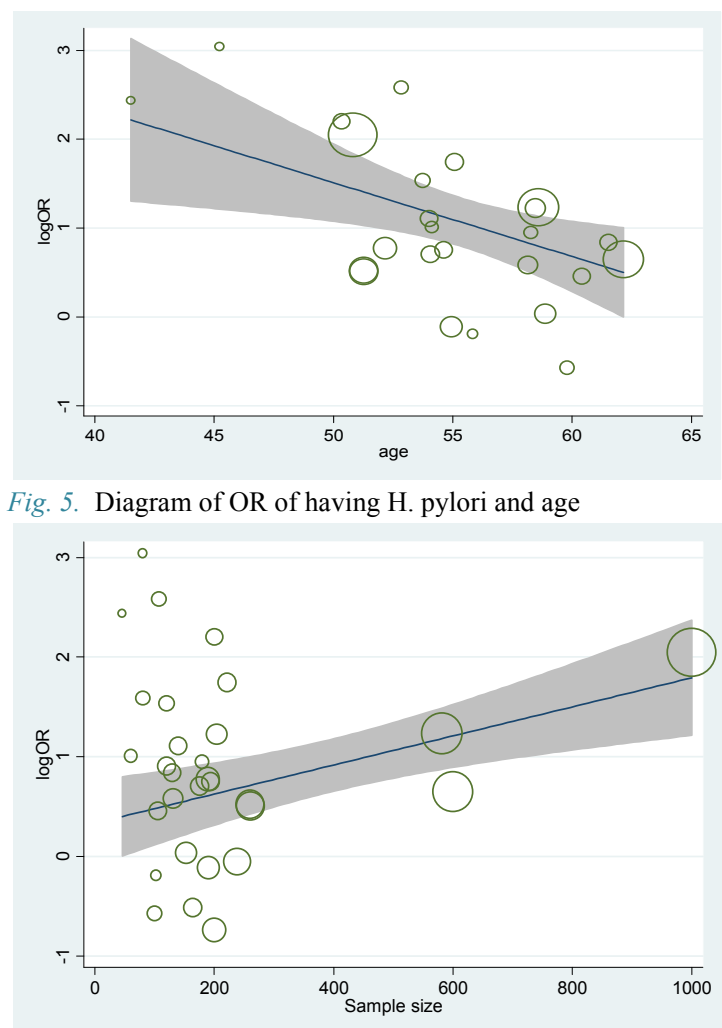

Fig. 6. Diagram of OR of having H. pylori and Sample size 


\begin{tabular}{|c|c|c|c|c|c|}
\hline Parameters & Coefficient & Standard errors & $\mathrm{t}$ & $\mathrm{P}>|\mathrm{t}|$ & [95\% Conf. Interval] \\
\hline Constant & 6.64 & 1.82 & 3.63 & 0.001 & {$[2.86,10.42]$} \\
\hline Age & -0.10 & 0.03 & -3.11 & 0.005 & {$[-0.17,-0.03]$} \\
\hline & Number of obs $=25$ \\
\hline \multicolumn{5}{|c|}{ REML estimate of between-study variance } & $\mathrm{Tau}^{2}=0.3415$ \\
\hline \multicolumn{5}{|c|}{$\%$ residual variation due to heterogeneity } & I-squared_res $=77.67 \%$ \\
\hline \multicolumn{5}{|c|}{ Proportion of between-study variance explained } & Adj R-squared $=26.67 \%$ \\
\hline
\end{tabular}

\begin{tabular}{|c|c|c|c|c|c|}
\hline Parameters & Coefficient & Standard errors & $\mathrm{t}$ & $\mathrm{P}>|\mathrm{t}|$ & [95\% Conf. Interval] \\
\hline Sample size & 0.001 & $<0.01$ & 0.93 & 0.35 & {$[-0.001,0.002]$} \\
\hline Constant & 0.68 & 0.24 & 2.76 & 0.01 & {$[0.17,1.18]$} \\
\hline Meta-regress & & & \multicolumn{3}{|c|}{ Number of obs 30} \\
\hline REML estim & udy variance & & \multicolumn{3}{|c|}{$\mathrm{Tau}^{2}=0.5865$} \\
\hline$\%$ residual $v$ & terogeneity & & \multicolumn{3}{|c|}{ I-squared_res $=79.99 \%$} \\
\hline Proportion $\mathrm{o}$ & ariance expla & & \multicolumn{3}{|c|}{ Adj R-squared $=2.24 \%$} \\
\hline
\end{tabular}

\begin{tabular}{|c|c|c|c|c|c|}
\hline Parameters & Coefficient & Standard errors & $\mathrm{t}$ & $\mathrm{P}>|\mathrm{t}|$ & [95\% Conf. Interval] \\
\hline Disease1 & -1.27 & 0.49 & -2.55 & 0.017 & {$[-2.3,-0.24]$} \\
\hline Disease2 & -1.7 & 0.46 & -3.63 & 0.001 & {$[-2.66,-0.74]$} \\
\hline Constant & 2.23 & 0.43 & 5.18 & $<0.001$ & {$[1.35,3.12]$} \\
\hline Meta-regression & & & \multicolumn{3}{|c|}{ Number of obs 30} \\
\hline REML estimate & udy variance & & \multicolumn{3}{|c|}{$\mathrm{Tau}^{2}=0.4102$} \\
\hline$\%$ residual variat & terogeneity & & \multicolumn{3}{|c|}{ I-squared_res $=81.40 \%$} \\
\hline The proportion $\mathrm{o}$ & Idy variance & & \multicolumn{3}{|c|}{ Adj R-squared $=31.63 \%$} \\
\hline Joint test for all c & & & \multicolumn{3}{|c|}{ Model F $(2,27)=6.79$} \\
\hline Prob $>$ F & & & \multicolumn{3}{|c|}{$=0.0041$} \\
\hline
\end{tabular}

more than those without the infection and after removing the lower quality articles, the OR was increased to 2.1 that was consistent with results of the present study. It is notable, however, that the OR of MI in Asian populations with Helicobacter infection was 1.75 times more than that of the control group. This shows that OR of Helicobacter infection in Iranian population is higher than that of other Asian countries (49). Consistently, a study in India reported that risk of MI in individuals with Helicobacter infection was 2.5 times more than that of those without the infection (29). In addition, several other studies have shown a relationship between Helicobacter infection and MI so that the group with the infection had higher OR of MI. Prevalence of Helicobacter infection was relatively high in both control and case groups (50-52).

Some authors have argued that Helicobacter pylori infection increases the risk of cardiovascular diseases. There are several mechanisms to explain how the infection increases the risk of heart diseases. It is believed that chronic inflammation caused by chronic infections may lead to advanced atherosclerosis, which in turn results in CAD. Chronic infection increases inflammatory metabolites such as cytokines, which in turn influences arteries motions, disrupts endothelium functions, and causes excessive contraction of small arteries. Increase in cytokines concentration has been reported in many patients with Helicobacter pylori infection. Higher concentration of cytokines increases leukocytes, which in turn increases the risk of inflammatory reaction in the patients with the infection. These inflammatory reactions may explain the correlation between Helicobacter pylori infection and heart diseases. Different bacterial and viral infections may have cross-reaction with classic risk factors of heart diseases such as smoking, hypertension, diabetes, lipid disor- ders, and other pre-inflammatory stimulators (e.g. homocysteine, free radicals, cytokines, and chemokines) so that the outcome would be local and systemic intra-artery inflammation, which in turn results in atherosclerosis and thrombosis(22). Taking into account that the bacteria can prevent blood supply to walls of the heart, Helicobacter pylori infection may directly act as a pathogen on the wall of arteries and cause coronary diseases or indirectly cause inflammation $(53,54)$. If the relationship between Helicobacter pylori infection and cardiovascular diseases is proven, one may conclude that treating the infection reduces OR of the diseases and the pertinent events.

\section{Conclusion}

Following a comprehensive research approach, the relationship between Helicobacter pylori infection and risk of heart diseases was examined. Thirty articles were surveyed, and the result showed that OR of heart diseases in the subjects with helicobacter pylori was two times more than that in the subjects without the infection. Since most of the hosts of the bacterium are afflicted with the infection in their childhood, personal hygiene promotion and preventive programs for children may have a considerable role in reducing the risk of the infection and cardiovascular diseases consequently.

\section{Limitations}

Although the results indicated that Helicobacter infection doubles OR of cardiovascular diseases, interpreting the data of the infections is not easy due to some disturbing variables such as childhood poverty and/or other similar factors. Future works need to take the socioeconomic condition of the participants into account in examining the relationship between the infection and 


\section{cardiovascular diseases}

\section{Conflict of Interests}

The authors declare that they have no competing interests.

\section{References}

1. Ridker PM. Inflammation, Infection, and Cardiovascular Risk How Good Is the Clinical Evidence? Circulation. 1998;97(17):1671-4.

2. Epstein SE. The multiple mechanisms by which infection may contribute to atherosclerosis development and course. Circulation Res. 2002;90(1):2-4.

3. Hosseini E, Poursina F, Van de Wiele T, Safaei HG, Adibi P. Helicobacter pylori in Iran: A systematic review on the association of genotypes and gastroduodenal diseases. J Res Med Sci. 2012 Mar; 17(3): 280-292.)

4. Bahar M, Faghihi Kashani A, Haghighat P, Kabir A, Poor Eslami M. Association between Helicobacter pylori infection and coronary heart disease. Razi J Med Sci.2004;11(39):13-21.

5. Rajasekhar D, Subramanyam G, Latheef SA, Vanajakshamma V, Srilatha A, Chaudhury A. Infectious aetiology in acute coronary syndromes. Indian J Med Microbiol.2002;20(2):83.

6. Tamura A, Fujioka T, Nasu M. Relation of Helicobacter pylori infection to plasma vitamin B12, folic acid, and homocysteine levels in patients who underwent diagnostic coronary arteriography.Am J Gastroenterol. 2002 Apr;97(4):861-6.

7. Tewari R, Nijhawan V, Mishra M, Dudeja P, Salopal T. Prevalence of Helicobacter pylori, cytomegalovirus, and Chlamydia pneumoniae immunoglobulin seropositivity in coronary artery disease patients and normal individuals in North Indian population. Med J Armed Forces India. 2012;68(1):53-7.

8. Patel P, Mendall M, Carrington D, Strachan D, Leatham E, Molineaux $\mathrm{N}$, et al. Association of Helicobacter pylori and Chlamydia pneumoniae infections with coronary heart disease and cardiovascular risk factors. Br Med J. 1995;311(7007):711-4.

9. Kinjo K, Sato H, Sato H, Shiotani I, Kurotobi T, Ohnishi Y, et al. Prevalence of Helicobacter pylori infection and its link to coronary risk factors in Japanese patients with acute myocardial infarction. Circ J.2002;66(9):805-10.

10. Folsom AR, Nieto FJ, Sorlie P, Chambless LE, Graham DY. Helicobacter pylori seropositivity and coronary heart disease incidence. Circulation. 1998;98(9):845-50.

11. McDonagh T, Woodward M, Morrison C, McMurray J, TunstallPedoe H, Lowe G, et al. Helicobacter pylori infection and coronary heart disease in the North Glasgow MONICA population. Eur Heart J.1997;18(8):1257-60.

12. Mendall MA, Goggin PM, Molineaux N, Levy J, Toosy T, Strachan $\mathrm{D}$, et al. Relation of Helicobacter pylori infection and coronary heart disease. Br Heart J.1994;71(5):437-9.

13. Danesh J, Peto R. Risk factors for coronary heart disease and infection with Helicobacter pylori: meta-analysis of 18 studies. Br. Med. J.1998;316(7138):1130-2.

14. Khodaii Z, Vakili H, Ghaderian SMH, Najar RA, Panah AST. Association of Helicobacter pylori infection with acute myocardial infarction. Coron Artery Dis.2011;22(1):6-11.

15. Rahimi FDM, Ahsani S, Tahernia R. Relationship between chlamydia infection with Helicobacter pylori, cytomegalovirus and heart disease caused by atherosclerosis. Pajoohandeh J. 2001;6(4):915.

16. Sarraf-Zadegan N, Amiri M, Maghsoudloo S. Helicobacter pylori relation to acute myocardial infarction in an Iranian sample. Coron Health care. 2001;5(4):202-7.

17. Rahnema B, Zadegan N, Fatahi E, Samadikhah J. Survey on the Association of Seropositivity of H.pylori IgG with Acute Myocardial Infarction. J Kerman Uni Med Sci.2001; 8(2): 66-73

18. Aghajani AM. Chronic infection with H. pylori and + CagA strain associated with coronary artery disease. Iran South Med J. 2002;5(1):56-62.

19. Jalali F. myocardial infraction and infections with helicobacter pylori and chlamydia pneumonia. Iranian Heart J.2003:4(1-2);34-38 .

20. Eskandarian RMM, Mousavi S, Babai M. Association of helicobacter pylori infection with cardiac syndrome X . Koomesh. 2005;6(2):131-4.

21. Bahar M, Faghihi Kashani A, Haghighat P, Kabir A, Poor Eslami M.
Association Between Helicobacter Pylori Infection and Coronary Heart Disease. Razi J Med Sci. 2004; 11 (39) :13-21

22. Eskandarian R, Malek M, Mousavi S, Babaei M. Association of Helicobacter pylori infection with cardiac syndrome X. Singapore Med J.2006;47(8):704.

23. Amrai A, Azemati M, Moghaddam M. Association between Helicobacter pylori infection with coronary heart disease. J Birjand Univ Med Sci. 2006;13(4):9-15.

24. Raygan F, Khorasanifar H, Momen Heravi M, Arj A, Akbari H. The association between acute myocardial infarction and anti helicobacter pylori antibody. Zahedan J Res Med Sci. 2009;11(2):0-.

25. Faghihi AH, Agah S, Fereshtehnejad SM, Bahar MA. Assessment of the relationship between serum fibrinogen level and chronic Helicobacter pylori infection in patients with or without. Med J Islam Repub Iran. 2007;21(2):105-10.

26. Pourya AMM, Sabzi F, Rezaei M, hoseinzadeghan H, Salehi M, Mozafari P. Investigate the relationship between Helicobacter pylori infection with Chlamydia pneumoniae and atherosclerosis. Yafte. 2014;2(1)

27. Bzazi H, Ghaemi E, pardeli H R , Ahmadi A Bazvari M Chlamydia pneumoniae antibodies in the serum of patients with acute coronary syndrome. Iranian J Infect Dis Trop Med.2008;13(40):11-4.

28. Sarrafzadegan N, Rezaporian P, Kaypour M, Mohseni M, Sadeghi M, Asgary S, et al. Prognostic value of infection and inflammation markers for late cardiac events in an Iranian sample. East Mediterran Health J.2008; 1;14(6).

29. Mohamadzadeh $\mathrm{MH}$, Behrozian R, Rahimi E. Investigate the relationship between Helicobacter pylori infection and cardiac syndrome X. J Shahrekord Univ Med Sci. 2008;11(1):58-63.

30. Akiash N, Nozari Y, EbrahimiDaryani N, Abdollahi A. Association between Helicobacter pylori infection and atherosclerotic coronary artery disease. Iranian J Pathol. 2009;4(1):1-4.

31. Bazzazi H, Ghaemi EA, Ramezani MA. The seroepidemiology of the chronic infections in patients with myocardial infarction in North of Iran. J Res Med Sci:2010;15(2):116.

32. Davoudi S, Omran AS, Boroumand MA, Rahimian N, Saadat S. Association between Helicobacter. pylori and coronary artery disease. Cent Eur J Med.2011;6(1):107-12.

33.Mirzababai H, Abolghasemi S, Aghanasiri Z, Alizadeh K. Evaluation of coronary artery disease and Helicobacter pylori infection. EbnesinaJ Med. 2010; 13 (1 and 2) :19-23)

34. Jafarzadeh A, Esmaeeli-Nadimi A, Nemati M, Tahmasbi M, Ahmadi P. Serum concentrations of Helicobacter pylori IgG and the virulence factor CagA in patients with ischaemic heart disease/Concentrations sériques d'IgG anti-Helicobacter pylori et facteur de virulence CagA chez les patients souffrant de cardiopathie ischémique. East Mediterr Health J. 2010;16:1039-44.

35. Khadem Ansari M, Rasmi Y, Manafi M , Rahimipour A, Ghadermarzi A. The evaluation of helicobacter pylori infection and cardiovascular disease risk factors with atherosclerosis. J Urmia Univ Med Sci. 2010;21(1):17-23.

36. Azarkar Z, Jafarnejad M, Sharifzadeh G. The relationship between helicobacter pylori infection and myocardial infarction. Caspian $\mathrm{J}$ Intern Med.2011;2(2):222.

37. Rasmi Y, Seyyed-Mohammadzad MH. Frequency of Helicobacter pylori and cytotoxine associated gene A antibodies in patients with cardiac syndrome X. J Cardiovasc Dis Res.2012;3(1):19-21.

38. Rogha M, Nikvarz M, Pourmoghaddas Z, Shirneshan K, Dadkhah D, Pourmoghaddas M. Is helicobacter pylori infection a risk factor for coronary heart disease? ARYA Atheroscler.2012;8(1):5.

39. S. Sayyah MAA-S, M. Tavakoli, AA. Pahlevan. Coexistence of gastric Helicobacter pylori infection and coronary artery diseases in Qazvin (Iran). J Qazvin Uni Med Sci.16(1):36-43.

40. Fouladi N, Alimohammadi Asl H, Amani F, Pourfarzi F, Homayunfar N, Karimollahi M, et al . Study of the Association between H. pylori Infection and Acute Coronary Syndrome. J Ardabil Univ Med Sci. 2012; 12 (1) :51-58

41. Honarmand H, Mirzajani E, Mirbolouk F, Rahbar-Taromsari M. Study on persistent bacterial and viral infections as risk factors for myocardial infarction. Annal Biol Res.2012, 3 (12):5612-5615

42. Vafaeimanesh J, Hejazi SF, Damanpak V, Vahedian M, Sattari M, Seyyedmajidi M. Association of Helicobacter pylori infection with coronary artery disease: is Helicobacter pylori a risk factor? Sci World J. 2014;2014:516354

43. Nejad ND, Mostafaei L, Jahanbakhshi F, Rashvand F, Alipour MH, 
Saroukhani MR. The Correlation of Infectious and Inherent Agents with Acute Myocardial Infarction in Patients of Teaching Hospitals in Qazvin in 2015. Access Lib J.August 2015 ; 2 :e1656

44. Prescott SL, Millstein RA, Katzman MA, Logan AC. Biodiversity, the Human Microbiome and Mental Health: Moving Toward a New Clinical Ecology for the 21st Century? Int. J. Biodiversity 2016, 2718275.

45. Danesh J. Is there a link between chronic Helicobacter pylori infection and coronary heart disease? Eur J Surg Suppl 1998;582:2731.

46. Sharma V, Aggarwal A. Helicobacter pylori: does it add to risk of coronary artery disease. World J Cardiol. 2015 Jan 26; 7(1): 19-25.

47. Izadi M, Fazel M, Sharubandi SH, Saadat SH, Farahani MM, Nasseri $\mathrm{MH}$, et al. Helicobacter species in the atherosclerotic plaques of patients with coronary artery disease. Cardiovasc Pathol. 2012;21(4):307-11.

48. Korosoglou G, Giusca S, Gitsioudis G, Erbel C, Katus HA. Cardiac magnetic resonance and computed tomography angiography for clinical imaging of stable coronary artery disease. Diagnostic classification and risk stratification. Front. Physiol. 2014;5:291.

49. Mann DL, Zipes DP, Libby P, Bonow RO. Braunwald's heart disease: a textbook of cardiovascular medicine: Elsevier Health Sciences; 2014.

50. Fraser A, Scragg R, Cox B, Jackson R. Helicobacter pylori, Chlamydia pneumoniae and myocardial infarction. Intern Med J. 2003;33(7):267-72.

51. Gunn M, Stephens J, Thompson J, Rathbone B, Samani N. Significant association of cagA positiveHelicobacter pylori strains with risk of premature myocardial infarction. Heart. 2000;84(3):26771.

52. Miyazaki M, Babazono A, Kadowaki K, Kato M, Takata T, Une H. Is Helicobacter pylori infection a risk factor for acute coronary syndromes? J Infect.2006;52(2):86-91.

53. Park MJ, Choi SH, Kim D, Kang SJ, Chung SJ, Choi SY, et al. Association between Helicobacter pylori seropositivity and the coronary artery calcium score in a screening population. Gut Liver. 2011;5(3):321-7.

54. Grdanoska T, Zafirovska P, Jaglikovski B, Pavlovska I, Zafirova B, Tosheska-Trajkovska K, et al. Chlamydia pneumoniae and helicobacter pylori serology-importance in patients with coronary heart disease. Mater Sociomed. 2012;24(3):151. 